\title{
Arbor
}

\section{El viaje de Don Pero Tafur (1436-1439)}

\section{Francisco Javier Villalba Ruiz de Toledo}

Arbor CLXXX, 711-712 (Marzo-Abril 2005), 537-550 pp.

En este breve análisis del viaje de Don Pero Tafur, hemos querido poner el acento en la percepción que tiene de Oriente un representante de la hidalguía castellana de la segunda mitad del siglo XV, para lo que resulta inestimable su relato autobiográfico. De ahi que únicamente nos detengamos en el recorrido que le lleva a las islas griegas, Tierra Santa, Egipto y el mundo bizantino y turco. Como aspecto complementario de esa atracción oriental para el hombre europeo de la época, dedicamos un espacio al encuentro del aventurero andaluz con el célebre mercader italiano, Niccolò dei Conti.

Las Andanças e viajes de Pero Tafur es, probablemente, uno de los Libros de Viaje más sobresalientes que nos ha legado la Edad Media peninsular. Desde luego no es el estilo literario lo que le confiere notoriedad, aunque sí un espíritu descriptivo que, en cierto modo, abre una nueva etapa en los relatos de viajeros con respecto a lo que venía observándose durante toda la época.

La tradición de la literatura castellana de los viajes a Oriente es más bien escasa antes de Pero Tafur. Si exceptuamos el viaje imaginario que sirviera para elaborar el Libro del conosçimiento de todos los reinos e tierras e señoríos que son por el mundo... ${ }^{1}$ a mediados del siglo XIV, únicamente podemos mencionar la Fazienda de Ultramar, escrito en la primera mitad del siglo XIII ${ }^{2}$, y la Embajada a Tamorlán a comienzos del siglo 
XV. El primero de ellos, que utiliza no pocos de los Libros de Viaje europeos aparecidos con anterioridad, tiene como principal objetivo convertir el itinerario descrito en una introducción al relato de los grandes pasajes bíblicos, expuestos con un plantamiento didáctico indudable. De hecho, los estudiosos de este texto lo han considerado siempre como una Biblia romanceada, antes que como un Libro de Viaje propiamente dicho. Tendremos ocasión de ver mas adelante cómo Pero Tafur no es capaz de resistirse a la tentación de transitar por esa misma dirección cuando nos narre las historias religiosas asociadas a los lugares que visita. El segundo, la Embajada a Tamorlán de Ruy González de Clavijo, proporciona a Tafur un planteamiento totalmente distinto, más enfocado hacia la descripción de las tierras y pueblos visitados, haciendo especial hincapié en sus tradiciones y forma de organización.

Las obra de Pero Tafur ha despertado un notable interés en la moderna historiografía, debido a lo cual contamos con varias ediciones y estudios, tanto dentro como fuera de nuestras fronteras. El único manuscrito que se conserva del texto es una copia de principios del siglo XVIII y fue editado por primera vez en $1874^{3}$.

A modo de introducción podemos indicar que el libro de Tafur contiene el relato de un viaje por Europa y el Próximo Oriente de tres años de duración -entre 1436 y 1439- narrado en primera persona por un hidalgo andaluz criado en la casa de Luis de Guzmán, maestre de Calatrava, a quien está dedicado el libro. Se describen en la obra varios viajes distintos, siendo el que corresponde a Oriente aquel que tiene lugar entre mayo de 1438 y el mismo mes del año siguiente. Más tarde repasaremos alguno de sus detalles más singulares. De momento nos conformaremos con adelantar la orientación que dicho relato ofrece a sus contemporáneos: las Andanças e viajes pretenden recuperar la vinculación del mundo cristiano con Oriente tras la pérdida de Constantinopla. Para ello se enaltecen a propósito los aspectos mágicos y fabulosos de los lugares visitados, recuperando todos los mitos medievales y tratando de elevarlos a la categoría de la experiencia contrastada. Hay que pensar que aunque la obra narra unos hechos ocurridos en los años señalados, su redacción hay que situarla después de 1453 , siendo bastante probable que el sentimiento de esa pérdida y peligro que supuso la entrada de la capital bizantina en la órbita turca, actuara como reclamo para que Pero Tafur se decidiera a escribir su experiencia de años atrás. 
El viaje de Don Pero Tafur (1436-1439)

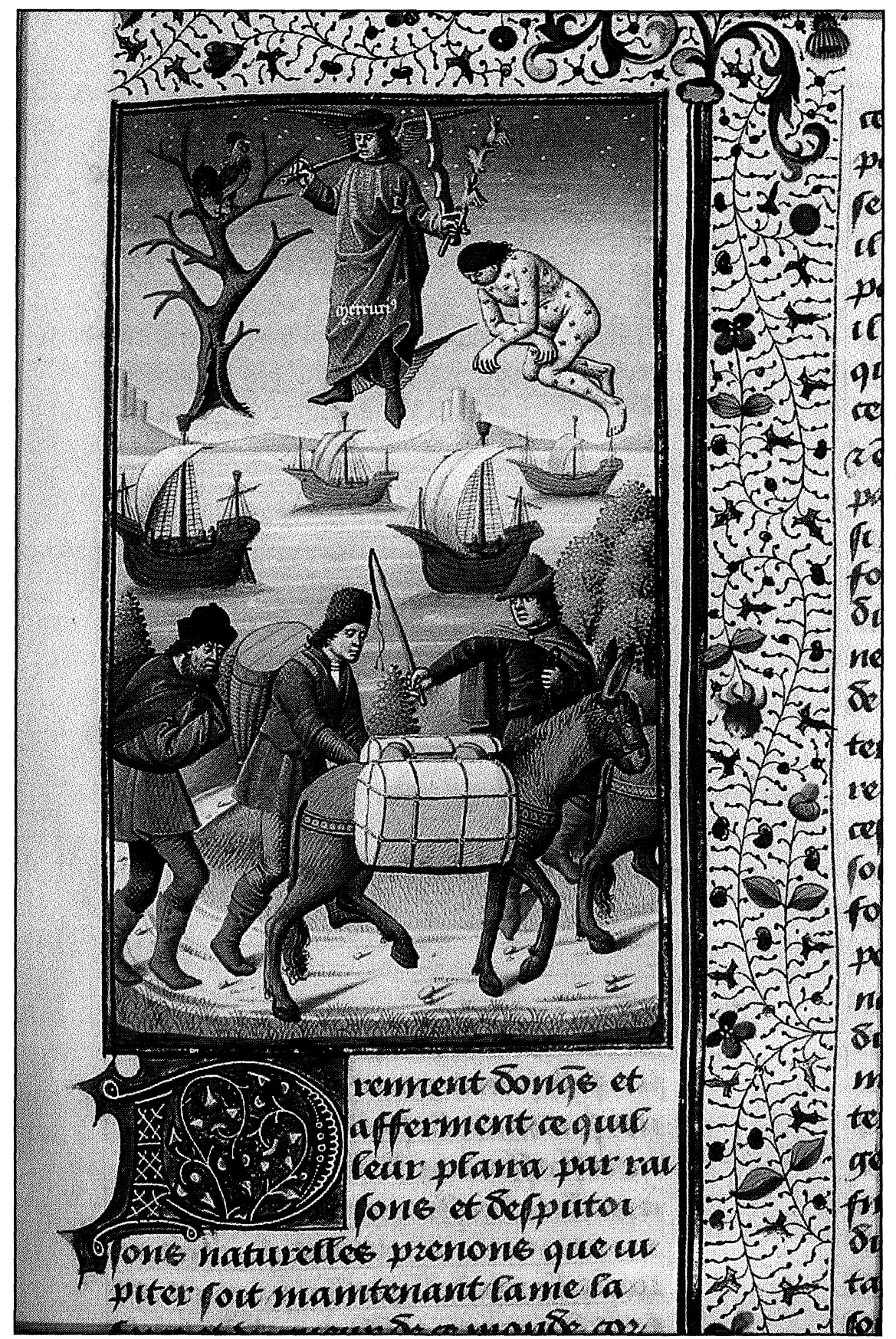

Miniatura representando a Mercurio como patrón de viajeros y protector contra las enfermedades. National Library of the Netherlands 


\section{Filiación de Pero Tafur}

Tal vez el tipo de obra que escribe Tafur no haga especialmente relevante, al menos desde el punto de vista histórico, detenerse a averigüar datos biográficos del mismo. Simplemente, y al objeto de ubicar sus observaciones en el marco de un grupo social determinado, repasaremos las informaciones que poseemos respecto a su actividad profesional y el lugar que ocupa en la sociedad tardomedieval a la que pertenecía.

Avalados por la documentación, podemos asegurar que unos años depués de escribir su obra, durante las décadas sesenta y setenta del siglo XV, Tafur estaba afincado en Córdoba, dedicado a la compra-venta de propiedades ${ }^{4}$, probablemente de cara a la formación de la herencia de sus hijos. Según la opinión de José Vives, debió de morir hacia 1480, momento en el que deja de aparecer su nombre en las actas capitulares cordobesas, circunstancia que ocurría con frecuencia hasta el año anterior en su calidad de veinticuatro de la ciudad ${ }^{5}$. Sin embargo, en atención a las constantes referencias que él mismo señala en su texto, debió nacer y vivir, al menos hasta la realización de su viaje, en Sevilla. Aunque todos los estudiosos de la figura de Tafur han dedicado muchos esfuerzos por ubicar el lugar exacto de su nacimiento, a nosotros nos parece un dato francamente irrelevante. Nos basta con saber que una buena parte de su existencia transcurre en tierras andaluzas y sobre todo, poner el acento en la proximidad de trato más o menos notoria con respecto a la alta nobleza. La posición social que llega a ocupar al final de su larga vida, queda reflejada en su condición de veinticuatro, cargo que también desempeñará después su hijo.

Testigo de los avatares de la más alta nobleza castellana del siglo XV, conviene enfatizar que Tafur debió criarse en la casa de Luis de Guzmán, maestre de Calatrava, a quien como ya hemos dicho dedica su obra, al tiempo que mantuvo algún contacto personal o institucional con el propio rey Juan II. Eso es al menos lo que se deduce de sus propias palabras cuando nos relata la existencia de cartas de recomendación que portó durante su largo viaje con el sello del rey castellano.

Con independencia del juicio que hagamos de su autocomplacencia cuando nos narra el valor y disposición que él mismo muestra siempre en la batalla, y al margen de que creamos o no unos episodios para los que tiene pocos testigos a su regreso, lo que está fuera de dudas es la admiración que siente Tafur por un modelo de comportamiento en el que los valores morales de corte religioso y de honor en la batalla, pueden servirnos para trasladarlo de forma inmediata a los hidalgos castellanos. Pero al mismo tiempo, Tafur participa de la relativa formación humanística que se respi- 
ra en las cortes europeas de la época, y entre las que la de Juan II no debía ser una excepción. Así se explica el entusiasmo con que asocia los mitos e historias del mundo clásico cuando viaja por Grecia y Roma, o la no menos llamativa inclinación a descubrir por sí mismo las maravillas de Oriente, para lo que más de una vez se jacta de haber puesto en peligro su vida. Pero además, su espíritu ilustrado le lleva a mantener un criterio de sistematización en su obra, de forma tal que siempre utiliza parámetros semejantes para la descripción y análisis de los lugares que describe, con los que pretende ofrecer una imagen lo más completa posible que abarque desde la potencialidad económica hasta las costumbres más significativas, pasando por las peculiaridades políticas o la presentación de los logros en la construcción o el diseño urbanístico.

\section{Elaboración de las Andanças e viajes.}

La obra de Tafur es verdaderamente atípica si consideramos que no muestra destreza literaria alguna, pese a poder clasificarse, al menos parcialmente, como un libro de aventuras, ni tampoco cabe atribuir a su autor oficio de historiador en la narración de acontecimientos o descripción de lugares. Las fuentes que pueden avalar sus afirmaciones, no sólo no se ofrecen al lector, sino que ni siquiera se somenten al análisis crítico más elemental. Tafur da crédito, sencillamente, a lo que recuerda haber escuchado en su viaje sobre el devenir histórico de cada lugar particular, sin molestarse en ocultar la procedencia mínimamente autorizada de quien oralmente le refiere los hechos. El rigor histórico es algo, pues, con lo que no podemos contar en las andanças e viajes.

Aunque Pero Tafur no da testimonio del momento preciso en que elabora su texto, varias referencias del mismo nos sitúan entre 1454 y 1457 como fecha probable de su redacción. Ya hemos señalado que la toma de Constantinopla por los turcos y su indudable efecto en la conciencia colectiva del occidente cristiano, fue lo que animó a rememorar los detalles de un viaje realizado dos décadas antes.

Es posible que Tafur llevara durante su periplo un cuaderno de notas con sus impresiones a modo de diario, del que se sirvió después para dar continuidad a su relato. Como cualquier turista moderno, el motivo de sus notas está impregnado por el deseo de transmitir a su vuelta las imágenes y sensaciones que ha tenido en el viaje. De ahí que la mayor parte de las veces se nos muestre una descripción visual acompañada de las peculiaridades de cada grupo poblacional. Sin embargo, al ser en aquel mo- 
mento absolutamente extraordinario la realización de un viaje tan largo en el tiempo y en el espacio, Tafur se ve a sí mismo como un pseudo embajador del rey castellano. El espíritu de la Embajada a Tamorlan de Ruy González de Clavijo salpica constantemente las páginas del aventurero andaluz, tratando de mostrar a sus contemporáneos el prestigio de Castilla en los lugares más remotos de la tierra. Llaman la atención, en ese sentido, los presentes que Tafur dice recibir en las distintas cortes que visita, hecho que siempre atribuye a su condición de emisario de Juan II.

Como ya dijimos antes, los mitos y referencias religiosas más importantes del bajo medievo están puntualmente recogidas en las Andanças $e$ viajes. Incluso podríamos decir que en varias ocasiones parece como si el objetivo final del viaje fuera el de testimoniar la existencia de los diferentes lugares que habían merecido algún tipo de veneración para el ámbito cultural del mundo cristiano. Así, en Tierra Santa, Pero Tafur relata la sistemática visita de todos los lugares en donde hay significación religiosa: el monasterio de San Jorge en la ciudad de Roma, donde, según él, descansa su cuerpo "e aun dizen que allí mató al dragón»; el monasterio de Monte Sion, el Santo Sepulcro, la casa de la Virgen María, el cenáculo, el monte Calvario, lugares concretos en los que se desarrolló la vida de Jesús, desde el huerto de los Olivos hasta la calle de la Amargura, y no pocas escenas bíblicas o de la vida de los santos, como el lugar en que fue lapidado San Esteban o la sepultura de la Virgen, todo ello en Jerusalem. Otro tanto ocurre en sus visitas a Belén -el pesebre, el lugar de nacimiento de San Juan Bautista-, Jericó -el lugar en que Juan bautizó a Jesús- o Betania -donde el diablo tentó a Jesús-.

\section{Los itinerarios del viaje}

En el estudio clásico de José Vives se puso ya de manifiesto la división del viaje de Tafur en cuatro grandes itinerarios: el primero desde la salida de Sanlúcar hasta Roma, que incluye la visita a ciudades como Pisa y Venecia; el segundo lleva a Tafur a Oriente, donde los grandes mitos y la imaginería medieval se nos presenta con toda su fuerza didáctica; el tercero le lleva hacia la Europa central; y el cuarto será el del viaje de regreso por el Adriático y el Mediterráneo ${ }^{6}$.

Nosotros vamos a centrarnos exclusivamente en el segundo de dichos itinerarios: aquel que tiene lugar entre el 9 de mayo de 1437 y el 22 de mayo del año siguiente. Desde Venecia, Tafur recorre la costa de la antigua Yugoslavia, Albania y Grecia. Desde la isla de Creta se dirige a Rodas 
e inmediatemente bordea la costa meridional de la actual Turquía para encaminarse hacia Haifa. Allí comienza su aventura por Tierra Santa. Su ya comentada vocación testimonial, le lleva a describir todos los detalles de su periplo por Jerusalem. Aunque su intención fuera pasar desde allí a la tierra del Sinaí -como veremos enseguida-, hubo de retroceder hacia el Líbano y Chipre para, desde allí, poner rumbo a Egipto. Realizará su visita a la tierra de los faraones como embajador del rey de Chipre.

En Egipto comienza la descripción de las maravillas de Oriente. A Tafur todo lo que ve le parece extraordinario y digno de ser incluído en su obra. En su condición de huésped del sultán, tiene acceso y guía para recorrer todos los lugares que desea, ofreciéndonos una estampa admirable del país bajo la atenta mirada de un occidental boquiabierto.

El itinerario cubierto desde Jerusalem a Egipto con escala en la isla de Chipre, obedece al deseo de Tafur de visitar el Sinaí. La imposibilidad de llevarlo a cabo desde Tierra Santa le obliga a realizar este largo recorrido. Pero una vez en Egipto puede alcanzar finalmente su objetivo. En el Sinaí tendrá lugar su encuentro con Niccolò dei Conti, siendo éste uno de los episodios más sobresalientes del relato de Tafur. La importancia del mismo invita a tratarlo con más detalle más adelante.

Una vez vuelto a Chipre para dar cuentas de su embajada, Tafur se dirige a Rodas, donde nos hace contemplar la muerte del maestre de la Orden del Hospital y la elección de Juan de Lastic como su sucesor al frente de los caballeros de San Juan de Jerusalem. Desde allí, Tafur se dirigió por mar a Constantinopla en un accidentado viaje que le obligó a recalar en la isla de Kios. Superadas las dificultades pone rumbo a Esmirna, en cuyas inmediaciones trató de encontrar los restos de la ciudad de Troya.

Ya en Constantinopla, Tafur coincide con varios embajadores de las cortes occidentales que tienen la misión de informar al emperador acerca de los logros y circunstancias relativas a la pretendida unión de las iglesias oriental y occidental. Entre ellos, según cuenta Tafur, se encuentra Alonso de Mata, escudero de Juan II de Castilla. Como no podía ser menos, Pero Tafur persigue entrevistarse con el propio emperador, Juan VII Paleólogo, quien colmando la vanidad del hidalgo, lo considera un miembro de su propia familia. Con las recomendaciones obtenidas en la corte de Constantinopla, Tafur viaja hasta Adrianópolis para entrevistarse con Murad II, emperador de los turcos otomanos, y más tarde, por el Mar Negro, llega hasta Trebisonda. En cualquier lugar que visite, el hidalgo andaluz aprecia y proclama la mayor altura moral de las costumbres cristianas, aunque sin dejar de admirarse por ciertas cualidades humanas que atesoran aquellos pueblos y, muy particularmente, la disposición urbanística que le recuerda el glorioso pasado de otras civilizaciones. 


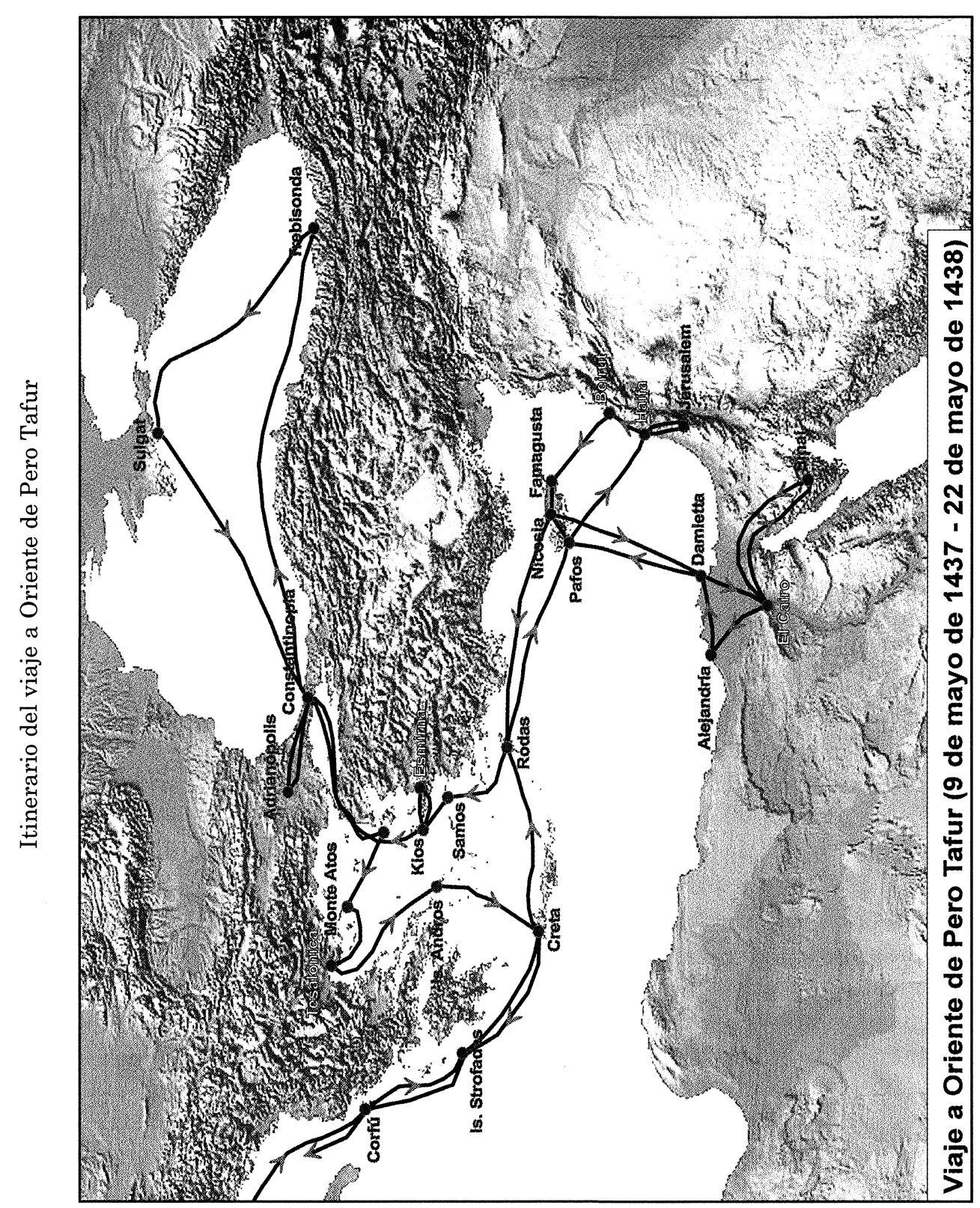


Llegado hasta Crimea, pone rumbo de nuevo hacia Constantinopla haciendo esta vez en la ciudad un exhaustivo recorrido turístico que nos proporciona una de las descripciones de la misma más sugerentes del mundo medieval. Asistimos, de la mano de Tafur, a la decadencia final de la ciudad que fue, durante toda la Edad Media, la más relevante de Europa. Contrasta enormemente el entusiasmo que embarga al autor al describir los soberbios templos y monumentos que recorre, con la lástima que siente hacia la población empobrecida y miserable que llena las calles.

\section{El encuentro con Niccolò dei Conti}

Es habitual en todos los estudios dedicados a los viajes y viajeros medievales prestar una especial atención al encuentro entre Pero Tafur y Niccolò dei Conti. Ello está plenamente justificado, no tanto por la veracidad del mismo o por las originales aportaciones del escritor andaluz -que admiten todo tipo de reservas y críticas-cuanto por lo que representa la incorporación de una "cuña" referida al mundo más oriental en un Libro de viajes como el que nos ocupa. José Vives dedicó un apartado del estudio dedicado a las Andanças e viajes a comparar las referencias que proporciona Tafur sobre el viajero italiano con las de Francesco Poggio Bracciolini. Nos remitimos, pues, a ese estudio para que cada cual extraiga sus propias conclusiones ${ }^{7}$.

La importancia del encuentro radica en la incorporación al texto de Tafur de la experiencia en Oriente de un comerciante y aventurero que durante mucho tiempo observó -e interpretó- ese mundo tan alejado de la realidad occidental. Niccolò dei Conti, nacido probablemente en 1395, partió en 1414 hacia Damasco por ser éste un centro caravenero de primera importancia. Desde allí se desplazará incesantemente llegando a conocer gran parte del continente asiático, especialmente su costa, que recorrió durante veinticinco años. Desde su condición de mercader tuvo ocasión de conocer todas las tierras que albergaban los grandes mitos de las civilizaciones de Oriente para el hombre medieval: desde la actual Irak hasta el sudeste asiático. En el transcurso de sus viajes llegó a formar una familia con la que terminó por abrazar el Islam, abjurando de su religión cristiana. Según refiere Tafur, tal decisión estuvo motivada por su propia seguridad personal y la de los suyos, pues fueron obligados a ello para salvar la vida. Desde su llegada a Italia en 1439 , y hasta 1449 , no sabemos nada de 
Conti. Es posible que ejerciera su oficio de mercader en Venecia. A partir de 1449 sabemos que, tal vez debido a su fama internacional, llega a desempeñar funciones de representación política para sus conciudadanos.

Si el episodio de Tafur es cierto, Conti se encontró con él cerca del Sinaí cuando se dirigía el comerciante a Florencia para solicitar el perdón del Papa Eugenio IV por haber renegado de su fe. Las fechas desde luego coinciden, aunque también hay que pensar que para cuando Tafur escribe su obra, Conti se había convertido en un afamado viajero e impulsor de las maravillas de Oriente. Veamos cómo el propio Tafur describe su encuentro con el mercader italiano: "Yo fui por la costa del mar Vermejo, que es media legua del monte de Synay, por ver como vinía la caravana, é fallé que vinía alli un veneciano que dezían Nicolo de Conto, gentil onbre de natura, é traya consigo su muger é dos fijos é una fija, que ovo en la India, é vinía él é ellos tornados moros, que los fizieron renegar en la Meca, que es su casa Santa» ${ }^{\text {. }}$.

Aunque no poseemos ningún relato de primera mano del italiano, el occidente medieval conocía de sobra sus aventuras a partir de los escritos del mencionado Poggio Bracciolini. Se trataba del secretario apostólico y posterior canciller de la República de Florencia, que durante la primera mitad del siglo XV encarna a la perfección el espíritu y la formación humanista, destacando en la recuperación y traducción al latín de todo tipo de manuscritos del mundo clásico. Entre su abundante obra personal, muy vinculada a los avatares del Concilio de Ferrara-Florencia, que luchaba por la recuperación de la unidad de las iglesias católica y ortodoxa, se encuentra la Historiae de varietate fortunae, que incluye en su Libro IV el relato de Niccolò dei Conti. Tal incorporación se explica por el interés mostrado entre los integrantes del Concilio hacia las comunidades cristianas que viven en un clima, si no hostil, al menos poco propicio para su normal desarrollo en las tierras de Oriente. La reunión conciliar que se prolonga entre 1438 y 1442 pretende anular los planteamientos dogmáticos diferenciadores que permitieron en su momento consolidar comunidades cristianas como la armenia, mesopotámica o caldea. Resulta conveniente tratar de entender las circunstancias particulares que habían llevado a tales comunidades a desviarse de los postulados de Roma, para lo que era absolutamente prioritario conocer sus condiciones de vida y formas de convivencia con otras religiones. El relato de Conti se convierte así, para Francesco Poggio Bracciolini, en un inmejorable testimonio de lo que ocurría en aquellas tierras. 


\section{El viaje de Don Pero Tafur (1436-1439)}

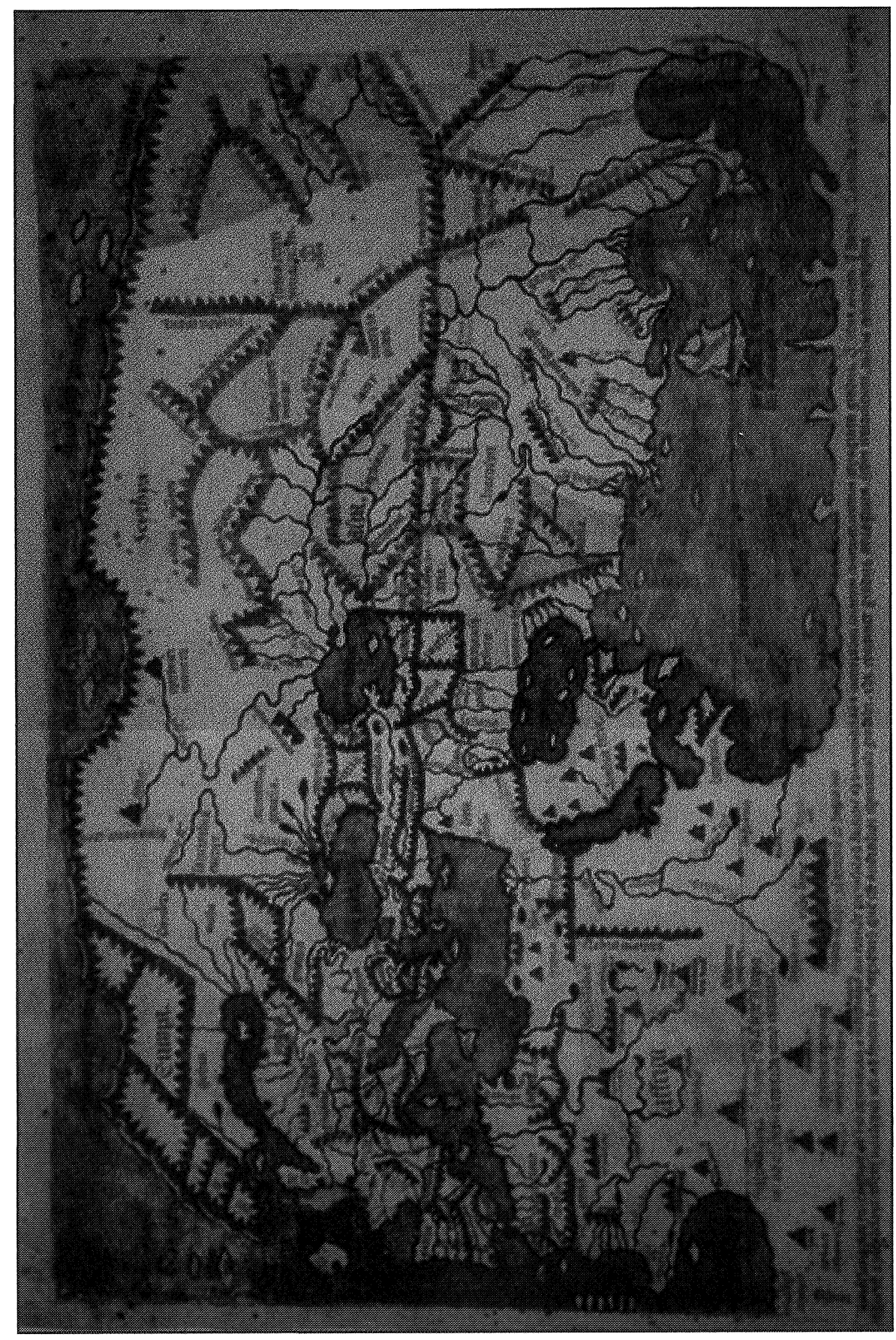

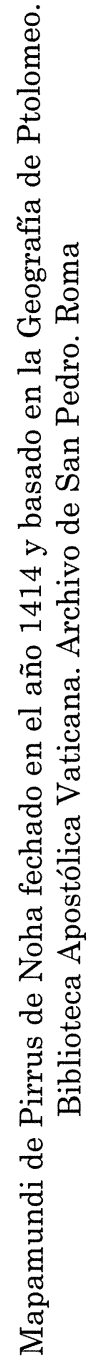


Toda la información del secretario apostólico acerca de las lejanas poblaciones de Oriente está perfectamente sistematizada en bloques coherentes que repasan la situación religiosa y costumbres elementales por un lado, informa sobre la rentabilidad física y posibilidades de riqueza del suelo por otro, y nos acerca a los usos jurídicos, rituales y rasgos culturales avanzados, como la lengua o los sistemas de comercio, por último.

Ignoramos las causas precisas que llevaron a Poggio a recopilar la información proporcionada por $\mathrm{Conti}^{9}$, pero lo que está fuera de toda duda es que su texto será complementado unos años después por Pero Tafur. Mientras el oficial de la Curia se centra en la sistematización de unos datos proyectados hacia el conocimiento de realidades lejanas, el aventurero andaluz nos ofrece material biográfico de Conti.

Con una mentalidad científica que es todavía una rareza en los años centrales del siglo XV, Poggio se acerca por medio de otras fuentes de información a la descripción de Etiopía, en la que no hay una sola referencia al legendario Preste Juan. Ese detalle tan singular nos permite aproximarnos con una cierta seguridad a las notas entresacadas del relato de Conti al mismo tiempo que explica el por qué de la ausencia de datos biográficos del mercader italiano. Pese a ello, no se renuncia a exponer el exotismo y peculiaridad del mundo oriental, sin el cual los potenciales lectores de su época no habrían tenido los suficientes alicientes como acercarse a su obra.

Francis M. Rogers puso hace ya muchos años de manifiesto la extraordinaria divulgación que, al menos en los ambientes eruditos del siglo $\mathrm{XV}$, tuvo la obra de Poggio ${ }^{10}$, y en particular el Libro IV de su Historiae de varietate fortunae. Aunque para fines diametralmente opuestos a los que persigue el secretario del Papa, Jacopo Filippo Foresti o Giuliano Dati utilizaron la documentación contenida en su texto para alimentar la figura mítica del Preste Juan. A ellos, como a Tafur, les mueve el ansia por aferrarse a las grandes referencias legendarias que definían un mundo que se les escapaba entre los dedos. No podemos olvidar que la segunda mitad del siglo XV es una de esas etapas históricas que en la que buena parte de la sociedad europea tiene conciencia de estar viviendo el final de un ciclo. Todos los valores encerrados en un código de la caballería que se ha ido nutriendo de valores y principios a través de los siglos, están dando paso a una visión más eficiente de las relaciones sociales y políticas, y son muchos los que se quedan atrapados voluntariamente en el pasado para no dar facilidades a un porvenir que no entienden.

$\mathrm{Al}$ margen de otras incorporaciones más o menos directas de la obra de Poggio ${ }^{11}$, conviene tener en cuenta las inmediatas traducciones que se 
llevan a cabo en lenguas vernáculas desde la redacción latina original. De 1502 data la primera de ellas elaborada por Valentín Fernandes al portugués, que acompañaba en el mismo volumen a otras narraciones de viajes, como el famoso Libro de las Maravillas de Marco Polo. Sin duda ninguna, el interés que por este tipo de relatos despiertan las iniciativas de los monarcas portugueses y españoles respecto a grandes expediciones ultramarinas a fines de la Edad Media, demandan el esfuerzo de traducción de obras como a las que estamos aludiendo. Sólo un año después, en 1503, el relato de Poggio era traducido también al castellano por Rodrigo de Santaella.

Pedro Tafur, como ya hemos dicho, nos proporciona un complemento muy interesante al texto de Poggio, pues aborda una sucinta biografía de Niccolò dei Conti por medio de la cual podemos entender mejor al personaje. Se le concede, por ejemplo, una gran importancia a esa renuncia obligada a la fe cristiana que condicionó siempre el modo de proceder del italiano durante los largos años de viajes ininterrumpidos por el continente asiático. Pero sobre todo conviene insistir en el hecho de que Tafur utiliza el encuentro con el mercader italiano para relatar una experiencia personal -aunque no propia-sobre el Extremo Oriente que remate adecuadamente su trabajo. Tafur necesita incorporar en su obra noticias sobre el reino del Preste Juan, el Paraíso Terrenal, la tierra milagrosa de la India o los detalles de los seres monstruosos que habitan esos recónditos lugares. Demuestra con ello ser un individuo mucho más identificado con la sociedad de su tiempo que el humanista y erudito Francesco Poggio Bracciolini, lo que le otorga un valor especial a su narración.

\section{Notas}

1 Se trata de una composición geográfica encubierta bajo el aspecto de un viaje personal, cuyo autor lo narra en primera persona. Son pocas las certezas que tenemos acerca de la autoría de semejante texto, si bien ha sido generalmente presentado como perteneciente a un monje franciscano. Si creemos en sus propias palabras, la única evidencia se refiere al momento de su nacimiento, en los primeros años del siglo XIV:«fuy nasçido en el reynado de Castilla reynante en uno el muy noble rey don Fernando fijo del muy noble Rey don Sancho quando andaua la era del mundo segund los abraicos en çinco mill e sesenta e çinco años e la era del general diluuio en cuatro mill e cuatroçientos e siete años e la era de nabucodonosor Rey de Caldea en dos mill e çincuenta e dos años e la era del grande Alixandre de Maçedonia en mill e seysçientos e diez e siete añose la era de Çesar enperador de Roma en mill e trezientos e quarenta e tres años e la era de Christus en mill e trezientos e quatro años e la era de los alarabes en sieteçientos e seys» Ed. de JiMÉnEZ DE LA EsPADA, M. (19877), Madrid, pp. 1-2. De los tres itinerarios que emprende, por la Europa nórdica, el Mediterráneo y los continentes africano y asiático respectivamente, 


\section{Francisco Javier Villalba Ruiz de Toledo}

nos interesan especialmente el segundo y el tercero. En ellos se hace un recorrido por la costa que, partiendo de Barcelona, bordea el sureste de Francia, Italia, la antigua Yugoslavia y Grecia para llegar finalmente a Constantinopla, desde donde se visita Chipre, Siria, Jerusalem, Egipto y la costa septentrional de África. Desde allí se vuelve hacia Etiopía en busca del mítico reino del Preste Juan y del Paraíso Terrenal para encaminarse después a la India, describiendo algunos lugares de Persia y Mesopotamia antes de dirigirse al Extremo Oriente, por donde alcanza la isla de Java. Ibid., pp. 65-71.

${ }_{2}$ Así lo cree DeYermond, A.D.(1994), Historia de la literatura española. La Edad Media, Barcelona, p. 140.

${ }^{3}$ La deficiente edición corrió a cargo de Marcos JIMÉNEZ DE LA ESPADA y formaba parte de la Colección de libros españoles raros o curiosos. A partir de entonces varios estudiosos y eruditos han tratado de ubicar al autor de las Andanças en el contexto histórico de la Sevilla del siglo XV, al tiempo que trataban de averigüar qué partes del relato son reales y cuáles imaginarias. José VIVES GATELL y Francisco LóPEZ EsTRADA, responsables de introducir la edición facsímil de JIMÉNEZ DE LA ESPADA, son, probablemente, los mayores especialistas. Remitimos precisamente al estudio de J. VIVES en la citada edición facsímil para la relación de investigadores que se acercaron, desde finales del siglo XIX, al estudio de la obra de Tafur: (reed. 1982) Andanças e Viajes de un hidalgo español. Pero Tafur, Barcelona, pp. 1-5. Sin embargo, y debido al hecho de detenerse tal estudio antes de mediados del siglo XX, citaremos aquí, como más recientes aportaciones, las obras de Rafael BELTRÁN (1991) «Los libros de viajes medievales castellanos. Introducción al panorama crítico actual: ¿cuántos libros de viajes medievales castellanos?», en Revista de Filología Románica, Madrid, anejo I, pp. 121-164, Filomena LIBERATORE (1986) «Pero Tafur, pellegrino e viaggiatore curioso» en Studi di Iberistighe, 7, pp. 90-99 o Sofía CARRIZO (1989) «El viaje y la crisis del mundo caballeresco en el relato de Pero Tafur», Actas del Congreso Internacional sobre Literatura Hispánica en la época de los Reyes Católicos y el Descubrimiento, Barcelona, pp. 417-422.

4 Así lo consigna R. RAMírez DE ARELlano (1901) «Estudios biográficos: Pero Tafur» en Boletín de la Real Academia de la Historia, 41, Madrid, pp. 278-298, quien cita documentos que abarcan el espacio cronológico que va de 1460 a 1477.

5 Vives Gatell, J. Op. cit. p. 6.

6 Ibid.. pp. 27-57.

7 Ibid. pp. 57-74.

8 Andanças e viajes, p. 95 .

9 El texto de Tafur sugiere que ello está directamente relacionado con esa petición de perdón al Papa, quien, seguramente a cambio del mismo, le obligaría a prestar declaración promenorizada de lo que vio y aprendió en sus viajes por Oriente a su secretario.

10 The Quest for Eastern Christians. Travels and Rumor in the Age of Discovery, Minneapolis, 1962.

11 Se han encontrado copias manuscritas de la Historiae de varietate fortunae en Italia, Francia, Alemania e Inglaterra, todas ellas del siglo XIV. 